\title{
General Thoracic
}

\section{Surgery}

\section{Restaging patients with N2 (stage Illa) non-small cell lung cancer after neoadjuvant chemoradiotherapy: A prospective study}

Robert James Cerfolio, MD, FACS, FCCP, ${ }^{a}$ Ayesha S. Bryant, MSPH, MD, and Buddhiwardhan Ojha, MD $^{\mathrm{c}}$

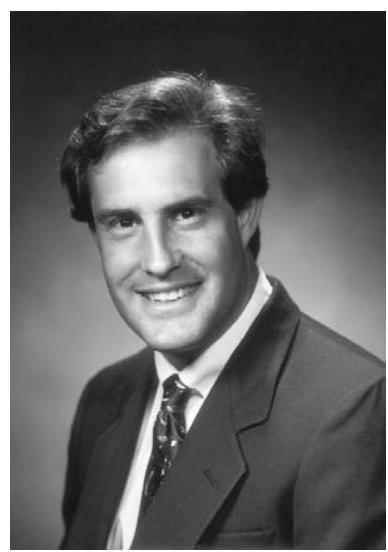

Dr Cerfolio

See related editorial on page 1227.

Earn CME credits at http:// cme.ctsnetjournals.org
Background: The accuracy of restaging in patients with stage IIIa non-small cell lung cancer after neoadjuvant chemoradiotherapy is unknown.

Methods: A prospective trial of patients with biopsy-proven N2 disease who underwent initial clinical staging with mediastinoscopy, integrated positron emission tomography/computed tomography (PET/CT), and CT. Patients then were clinically restaged by the same imaging techniques 4 to 12 weeks after their induction chemoradiation therapy and then underwent definitive pathologic staging.

Results: Ninety-three patients had their lymph nodes pathologically restaged. Repeat PET/CT after neoadjuvant therapy missed residual N2 disease in 13/65 (20\%) patients and falsely suggested it in 7 of $28(25 \%)$. It was more accurate than repeat CT for restaging at all pathologic stages (stage $0,92 \%$ vs $39 \%, P=.03$; and stage I $89 \%$ vs $36 \%, P=.04)$. When the maximum standardized uptake value of the primary tumor is decreased by $75 \%$ or more, it is highly likely (likelihood ratio, $+\mathrm{LR}, 6.1$ ) the patient is a complete responder; when it decreased by $55 \%$ or more, it is highly likely (+LR, 9.1) the patient is a partial responder. When the maximum standardized uptake value of the $\mathrm{N} 2$ node initially involved with metastatic cancer is decreased by more than $50 \%$, it is highly likely $(+\mathrm{LR}, 7.9)$ the node is now benign.

Conclusion: Repeat integrated PET/CT is superior to repeat CT for the restaging of patients with stage IIIa non-small cell lung cancer. The percent decrease in the maximum standardized uptake value of the primary and of the involved lymph node is predictive of pathology; however, nodal biopsies are required since a persistently high maximum standardized uptake value does not equate to residual cancer.

\footnotetext{
From the Division of Thoracic Surgery, University of Alabama at Birmingham, and the Division of CardioThoracic Surgery, Department of Surgery, Birmingham Veterans Administration Hospital ${ }^{\mathrm{a}}$; the Department of Epidemiology, University of Alabama at Birmingham School of Public Health ${ }^{\text {b }}$, and the Division of Nuclear Radiology, University of Alabama, ${ }^{\mathrm{c}}$ Birmingham, Ala.

Received for publication May 30, 2005; revisions received Aug 24, 2005; accepted for publication Aug 30, 2005 .

Address for reprints: Robert J. Cerfolio, MD, Associate Professor of Surgery, Chief of Thoracic Surgery, Division of Cardiothoracic Surgery, University of Alabama at Birmingham, 1900 University Blvd, THT 712, Birmingham, AL 35294 (E-mail: Robert.cerfolio@ccc.uab.edu).

J Thorac Cardiovasc Surg 2006;131:1229-35

$0022-5223 / \$ 32.00$

Copyright (C) 2006 by The American Association for Thoracic Surgery

doi:10.1016/j.jtcvs.2005.08.070
} 
$\mathrm{S}$ urgical resection in patients with stage IIIa N2 NSCLC usually is reserved for those who have had their nodes downstaged after neoadjuvant therapy. However, clinical restaging in these patients often is misleading. Mediastinoscopy, which is used most frequently to prove N2 disease, is not commonly repeated. Repeat mediastinoscopy often is inaccurate $e^{1,2}$ and associated with increased risk. ${ }^{2,3}$ Although endoscopic ultrasonography with fine-needle aspirate (EUS-FNA) can be repeated safely and is accurate, ${ }^{4,5}$ it is not available at most centers. Thus, the surgeon often is left to restage patients on the basis of repeat computed tomography (CT) scans, and repeat integrated positron emission tomography/computed tomography (PET/ CT) using 2-deoxy-2-18F-fluoro-D-glucose.$^{6-9}$ In a large prospective study of 383 patients, we showed that integrated $\mathrm{PET} / \mathrm{CT}$ is only $67 \%$ accurate in staging patients who never received neoadjuvant therapy. ${ }^{10}$ Patients who received neoadjuvant therapy were excluded from that trial because of their participation in this prospective study. The purpose of this study was twofold: to assess the accuracy of repeat integrated PET/CT versus repeat $\mathrm{CT}$ and to evaluate the change in the maxSUV of the primary tumor and of the involved mediastinal lymph node after neoadjuvant chemoradiotherapy in patients with stage IIIa NSCLC.

\section{Methods}

\section{Entry Criterion}

Between September 2002 and August 2004, all patients with NSCLC who presented to one surgeon (R.J.C.) and who underwent integrated PET/CT at our institution, underwent a CT scan, had biopsy-proven N2 disease by mediastinoscopy, and received chemoradiotherapy were eligible to participate in this study. Mediastinoscopy before neoadjuvant therapy was required for entry into this study to rule out N3 disease. Patients were excluded if they were younger than 19 years, had a history of type 1 diabetes, or had N3 disease. All suspicious sites of nodal or metastatic disease suggested by PET/CT (maxSUV > 2.5) and CT scan were investigated. All patients received carboplatinum-based chemotherapy and radiotherapy. The repeat PET/CT and CT scan were performed no sooner than 4 weeks and no later than 12 weeks after completion of the neoadjuvant chemoradiotherapy. All patients were staged clinically and restaged by using the TNM classification system. ${ }^{11}$ An initial clinical stage (later confirmed to be N2 after biopsy) was assigned for each patient on the basis of the integrated PET/CT scan, which was read by a nuclear radiologist and on the basis of the CT scan, which was read by a chest radiologist. After completion of the therapy a post-therapy pathologic stage was determined by repeat biopsy or resection.

\section{Radiologic Imaging}

Both the initial and the repeat PET/CT were performed on an integrated PET/CT scanner (GE Discovery LS PET/CT Scanner; General Electric, Milwaukee, Wis). Patients were asked to fast for 4 hours and then subsequently received $555 \mathrm{MBq}(15$ $\mathrm{mCi}$ ) of fluorodeoxyglucose (FDG) intravenously, followed by PET after 1 hour. The scanning time for emission PET was 5
Abbreviations and Acronyms
EUS-FNA = endoscopic ultrasonography with fine- needle aspirate
FDG = fluorodeoxyglucose
MRI = magnetic resonance imaging
maxSUV $=$ maximum standardized uptake value
NSCLC = non-small cell lung cancer
$\mathrm{PET} / \mathrm{CT}=$ positron emission tomography/computed tomography
ROC = receiver operator characteristic

minutes per bed position. Iterative reconstruction with $\mathrm{CT}$ attenuation correction was performed. In addition, the most recent CT scan of the chest also was available for visual correlation. The maxSUV of the primary and each suspicious lymph node station was calculated and determined by drawing regions of interest on the attenuation-corrected FDG-PET images around it as described previously. ${ }^{12}$

\section{Procedures/Staging}

Patients were staged meticulously. All nodal sites (N2 and N3) with a maxSUV of 2.5 or greater were biopsied before pulmonary resection. Mediastinoscopy, which was performed on all patients, was used to biopsy suspicious lymph nodes in the $2 \mathrm{R}, 4 \mathrm{R}, 2 \mathrm{~L}, 4 \mathrm{~L}$ (paratracheal), and 7 (subcarinal) stations; transesophageal EUSFNA was used to biopsy nodes in the 5 stations (posterior aortopulmonary window), 7 (subcarinal), 8 (periesophageal), and 9 (inferior pulmonary ligament nodes). EUS-FNA was performed only if the PET/CT or the CT suggested metastatic cancer in the 5, $6,7,8$, or 9 stations. All metastatic (M1) sites were investigated further with biopsies and/or appropriate tests. Figure 1 depicts the current restaging algorithm used. EUS was performed by a single

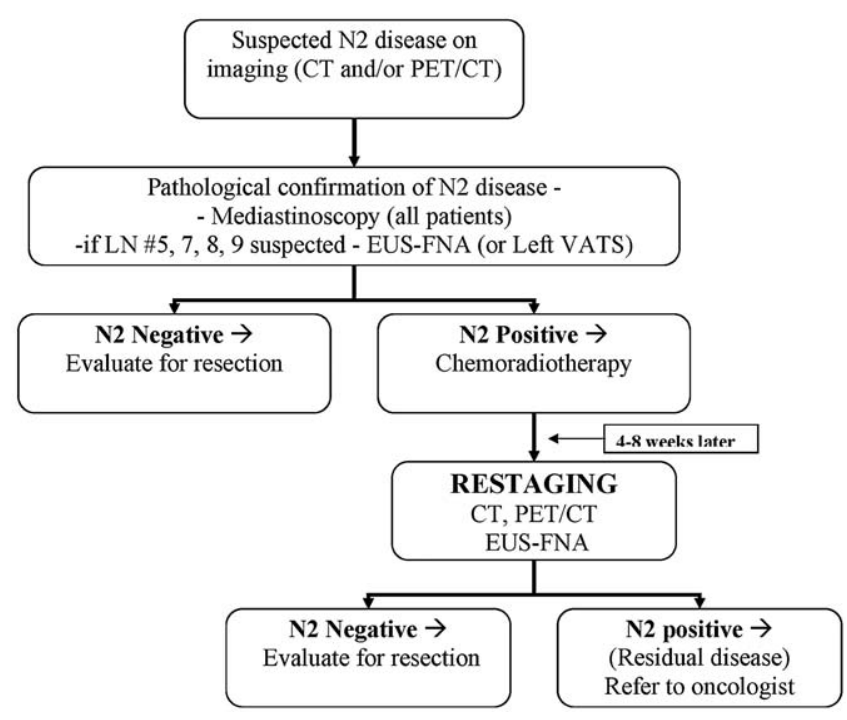

Figure 1. Staging algorithm for patients with suspected N2 disease. 


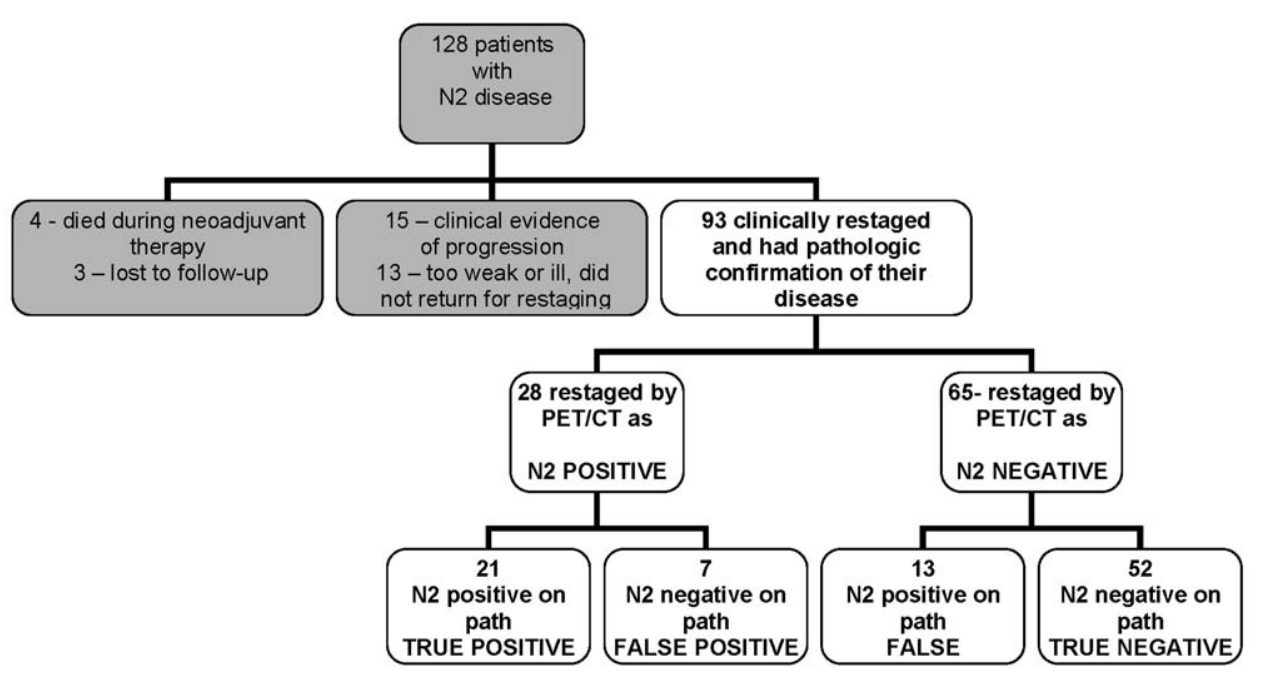

Figure 2. Outcomes of the 128 patients with biopsy-proven N2 disease eligible for this study.

experienced endosonographer as described previously. ${ }^{13}$ In general, targets provided by PET/CT and/or CT underwent a biopsy; however, if EUS did not identify any anatomic structure for a biopsy, FNA was not performed.

Patients with suspected M1 disease in the liver, adrenal, or contralateral lung underwent definitive biopsy to prove or disprove M1 cancer. If the bone or brain was suspected to harbor metastases, magnetic resonance imaging (MRI) was considered the standard reference. If patients had biopsy-proven N3 or M1 disease, the stage was recorded but not entered in this study. Only those with biopsy-proven N2 disease were eligible for this study. Pathologic review was performed via standard techniques, and immunohistochemical staining was employed when appropriate. The pathologic stage was assessed by using the international staging system. $^{11}$

A patient was defined as having unsuspected $\mathrm{N} 2$ disease in this study if neither the repeat PET/CT nor the repeat CT suggested any cancer remained in any of the N2 nodes but the patient had pathologic proof of metastatic NSCLC cancer in at least one N2 node. Residual N2 disease was defined as persistent, biopsyproven NSCLC in an N2 lymph node after completion of chemoradiotherapy in the same node that was proven initially to harbor cancer. The University of Alabama at Birmingham's institutional review board approved both the electronic prospective database used for this study and this prospective trial.

\section{Statistical Analysis}

Accuracy was determined for repeat PET/CT and CT by using the pathology results as the gold standard. The optimal percentage of decrease in maxSUV that was related to the likelihood of having a response to neoadjuvant therapy was determined with the use of receiver operator characteristics (ROC) curve analysis. The optimal cutoff point was the percentage of decrease that yielded minimal false-positive and false-negative results. The $\mathrm{C}$-index also is reported (an area of 0.5 indicates no predictive discrimination, and an area of 1.0 indicates perfect separation of patients with different outcomes ${ }^{14}$ ). Analysis was performed with SAS 9.0 (SAS Institute, Cary, NC).

\section{Results}

There were 128 patients (84 men) who presented with biopsy-proven N2 disease. Ninety-three of these patients were restaged pathologically after neoadjuvant chemoradiotherapy (Figure 2). The types of tumor, procedures used to prove N2 disease, and distribution of N2 disease are shown in Table 1. The pathologic stage after the completion of neoadjuvant therapy also is shown in Table 1 . The accuracy for assessment of pathologic stage by PET/CT and CT was $92 \%$ versus $39 \%(P=.03)$ for stage $0,89 \%$ versus $36 \%$ $(P=.04)$ for stage I, $85 \%$ versus $83 \%(P>.05)$ for stage II, $69 \%$ versus $67 \%(P>.05)$ for stage III, and $85 \%$ versus $80 \%(P>.05)$ for stage IV.

Figure 2 shows the outcome of patients eligible for this study. Table 2 depicts the distribution of the unsuspected N2 disease in the 13 patients who were staged clinically as N2 negative on PET/CT but had pathologically proven N2 disease (false negatives). The most common locations for unsuspected N2 disease were the number 7 lymph node station (6 patients), the number 6 lymph nodes (6 patients), and the number 5 lymph node station (3 patients).

Table 3 depicts the decrease in the maxSUV of the primary tumor on the basis of the pathologic stage. Patients who were complete responders had the greatest median decrease in their maxSUV (100\%) of the primary tumor. Those who were downstaged and were partial responders (were N2 negative but still had surviving cancer cells in the primary resected tumor) had a median decrease of $68 \%$ $(P=.01)$, and those who had residual N2 disease had a decrease of only $32 \%(P<.001)$. 
TABLE 1. Patient characteristics

\begin{tabular}{|c|c|}
\hline Patients who initially presented with & 128 nationts \\
\hline IN2 Or INS uisease & \\
\hline Median age (range) (y) & $67(34-78)$ \\
\hline Gender & \\
\hline Male & 84 \\
\hline Female & 44 \\
\hline Histology & \\
\hline Squamous cell carcinoma & 33 \\
\hline Adenocarcinoma & 48 \\
\hline Bronchoalveolar carcinoma & 9 \\
\hline Neuroendocrine & 5 \\
\hline Carcinoid & 9 \\
\hline $\begin{array}{l}\text { Other type of, mixed, or } \\
\text { nonspecified NSCLC }\end{array}$ & 24 \\
\hline $\begin{array}{l}\text { Procedures used to document N2 } \\
\text { disease* }\end{array}$ & \\
\hline Mediastinoscopy & 128 \\
\hline EUS-FNA & 32 \\
\hline Left VATS biopsy & 9 \\
\hline Other (Chamberlin) & 1 \\
\hline Distribution of initial N2 disease & \\
\hline $2 \mathrm{R}, 2 \mathrm{~L}, 4 \mathrm{R}$, or $4 \mathrm{~L}$ & 72 \\
\hline 5 or 6 & 25 \\
\hline 7,8, or 9 & 31 \\
\hline $\begin{array}{l}\text { Mean duration between } \\
\text { neoadjuvant therapy and } \\
\text { restaging }\end{array}$ & 5.9 wk (range, 4.1-10.3 wk) \\
\hline Restaging information & 93 patients \\
\hline $\begin{array}{l}\text { Pathologic stage after } \\
\text { neoadjuvant therapy } \dagger\end{array}$ & \\
\hline 0 & 14 \\
\hline 1 & 22 \\
\hline II & 15 \\
\hline III & 37 \\
\hline IV & 5 \\
\hline $\begin{array}{l}\text { No. of patients found to have } \\
\text { unsuspected } \mathrm{N} 2 \text { disease } \\
\text { after pathologic restaging or } \\
\text { resection }\end{array}$ & $13(14 \%)$ \\
\hline
\end{tabular}

EUS-FNA, Endoscopic ultrasonography with fine-needle aspirate; NSCLC, non-small cell lung cancer; VATS, video-assisted thoracic surgery. *Some patients had $>1$ procedure. $†$ Excludes patients who were not pathologically restaged.

Table 4 depicts the change in the maxSUV of the lymph node initially involved with biopsy-proven cancer after neoadjuvant therapy. It shows a $87 \%$ decrease in the 59 patients whose nodes were rendered benign, compared with only a $62 \%$ decrease in the 34 patients whose nodes harbored residual disease $(P=.02)$. Figure 3 depicts the change in the maxSUV stratified by different lymph node stations. The greatest fall in the maxSUV occurred in the paratracheal ( $2 \mathrm{R}$ and $4 \mathrm{R})$ nodes, compared with the aortopulmonary nodes (5 and 6) and the subcarinal node (7).
TABLE 2. The distribution of unsuspected N2 disease after restaging on the basis of $\mathrm{PET} / \mathrm{CT}^{*}$

\begin{tabular}{|c|c|c|c|c|}
\hline \multirow{2}{*}{$\begin{array}{l}\text { Clinical stage by } \\
\text { PET/CT after } \\
\text { neoadjuvant } \\
\text { therapy }\end{array}$} & \multirow[b]{2}{*}{$\begin{array}{c}\text { No. of } \\
\text { patients }\end{array}$} & \multirow{2}{*}{$\begin{array}{l}\text { No. of patients } \\
\text { with unsuspected } \\
\text { N2 disease }\end{array}$} & \multicolumn{2}{|c|}{$\begin{array}{c}\text { Location of } \\
\text { unsuspected N2 } \\
\text { disease }\end{array}$} \\
\hline & & & Nodes & $\begin{array}{c}\text { No. of } \\
\text { patients }\end{array}$ \\
\hline Stage 0 & 12 & $1(8.3 \%)$ & 6,7 , and 9 & 1 \\
\hline Stage I & 22 & $5(23 \%)$ & 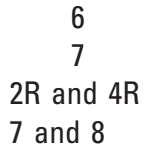 & $\begin{array}{l}2 \\
1 \\
1 \\
1\end{array}$ \\
\hline Stage II & 14 & $5(36 \%)$ & $\begin{array}{r}5 \text { and } 6 \\
7 \\
8\end{array}$ & $\begin{array}{l}1 \\
3 \\
1\end{array}$ \\
\hline Stage III & 33 & $1(3 \%)$ & 5 & 1 \\
\hline Stage IV & 12 & $1(8.3 \%)$ & 5 and 6 & 1 \\
\hline
\end{tabular}

PET/CT, Positron emission tomography/computed tomography. *Excludes patients who were not pathologically restaged.

ROC curve analysis, as seen in Figure 4, $A$, demonstrated an optimal decrease in the maxSUV of $75 \%$ or more (+LR, $6.1)$ to be indicative of a complete responder. Similarly, a decrease in the maxSUV of $55 \%$ or more (+LR, 9.1) predicted a patient as a partial responder, as shown in Figure 3 . The most accurate cutoff point to predict a lymph node's complete response was a fall in the maxSUV of the node of $50 \%$ (+LR, 7.9), as shown in Figure 4, B. When the data was stratified by specific lymph node stations (stations $2+4$, compared with stations $5+6$, and with station 7) a smaller decrease in the maxSUV of the nodes in stations 2 and 4 was required to predict downstaging than that seen for the other stations $(40 \%,+\mathrm{LR}, 7.1 ; 50 \%,+\mathrm{LR}, 4.9$; and $50 \%$, +LR, 5.1, respectively). The percentage of decrease in maxSUV was predicted better at the $2+4$ lymph node stations $(\mathrm{C}=0.84)$, compared with the $5+6(\mathrm{C}=0.68)$ and 7 stations $(\mathrm{C}=0.72)$.

TABLE 3. The median percentage decrease in the maxSUV of the primary on the basis of pathologic restaging

\begin{tabular}{lcc}
\hline $\begin{array}{l}\text { Response } \\
\text { (pathology proven) }\end{array}$ & $\begin{array}{c}\text { No. of } \\
\text { patients* }\end{array}$ & $\begin{array}{c}\text { Median \% decrease in the } \\
\text { maxSUV of the } \\
\text { primary tumor (range) }\end{array}$ \\
\hline $\begin{array}{l}\text { Complete responders } \\
\text { (T0 N0 M0) }\end{array}$ & 14 & $100 \%(75 \%-100 \%)$ \\
$\begin{array}{c}\text { Downstaged (excluding } \\
\text { complete responders) }\end{array}$ & 41 & $68 \%(2 \%-100 \%)$ \\
\begin{tabular}{l} 
Residual N2 disease \\
\hline
\end{tabular} & 32 & $32 \%(-5 \%-82 \%)$ \\
\hline
\end{tabular}

maxSUV, Maximum standardized uptake value. *Not all patients had restaging of $\mathrm{T}$ stage. 
TABLE 4. Percentage decrease in the maxSUV of the biopsy-proven N2-positive lymph node after pathologic restaging

\begin{tabular}{|c|c|c|c|c|}
\hline & \multirow[b]{2}{*}{$\begin{array}{c}\text { No. of } \\
\text { patients }\end{array}$} & \multicolumn{2}{|c|}{$\begin{array}{l}\text { Location of initially } \\
\text { involved N2 node }\end{array}$} & \multirow{2}{*}{$\begin{array}{c}\text { Median } \% \\
\text { decrease of } \\
\text { maxSUV* (range) }\end{array}$} \\
\hline & & Node & $\begin{array}{c}\text { No. of } \\
\text { patients }\end{array}$ & \\
\hline $\begin{array}{l}\text { Responder } \\
\qquad(\mathrm{N} 2 \rightarrow \mathrm{N} 0)\end{array}$ & 59 & $\begin{array}{l}2 \mathrm{R} \text { and } 4 \mathrm{R} \\
5 \text { and } 6 \\
7 \\
8 \text { and } 9\end{array}$ & $\begin{array}{r}36 \\
13 \\
16 \\
4\end{array}$ & $87 \%(2 \%-100 \%)$ \\
\hline $\begin{array}{l}\text { Residual N2 } \\
\text { disease } \\
(\mathrm{N} 2 \rightarrow \mathrm{N} 2)\end{array}$ & 34 & $\begin{array}{l}2 \mathrm{R} \text { and } 4 \mathrm{R} \\
5 \text { and } 6 \\
7 \\
8 \text { and } 9\end{array}$ & $\begin{array}{r}10 \\
12 \\
13 \\
3\end{array}$ & $52 \%(-16 \%-84 \%)$ \\
\hline
\end{tabular}

maxSUV, Maximum standardized uptake value. $* P<.02$.

\section{Discussion}

In 2004, 170,000 Americans were diagnosed with NSCLC, and almost 1 in 5 patients presented with $\mathrm{N} 2$ or stage IIIa disease. ${ }^{15}$ Recent studies have shown that patients who are downstaged via neoadjuvant therapy and then undergo resection have a significantly longer 5-year survival of $40 \%$ to $50 \%{ }^{16-18}$ than do those who have residual N2 disease. ${ }^{19}$ Thus, identification of patients who are N2 negative after completion of their neoadjuvant therapy is a critical component for patient selection for thoracotomy.

Most patients who are pathologically diagnosed with N2 disease have had mediastinoscopy. Repeat mediastinoscopy often is inaccurate ${ }^{1,3}$ and potentially dangerous, especially after chest irradiation. Van Schil and associates ${ }^{2}$ in 2002 reported on 27 patients who underwent repeat mediastinoscopy after neoadjuvant therapy and found that 4 of the 16 $(25 \%)$ patients were false negatives. Mateu-Navarro and associates ${ }^{1}$ in 2000 reported on 24 patients and 5 of the 12 had false-negative N2 disease. Some surgeons have used EUS-FNA to rebiopsy stations $5,7,8$, and 9 , but most endosonographers are unable to adequately visualize the lower paratracheal nodes well. ${ }^{20}$ Annema and colleagues ${ }^{5}$ in 2003 reported $83 \%$ accuracy for repeat EUS-FNA in 19 patients after neoadjuvant chemoradiotherapy. However, EUS is available in only a few centers. Thus, the surgeon is often left with the clinical stage, as assessed via repeat PET/CT and CT, to guide him or her. Therefore, we evaluated the accuracy of these repeat imaging modalities after neoadjuvant therapy.

In this prospective study we found that repeat integrated FDG-PET/CT was a better predictor than repeat CT of the pathology at all stages and, thus, of mediastinal nodal disease. This superiority achieved statistical significance for those patients with pathologic stage 0 and I disease. The accuracy of repeat PET/CT was best for complete respond-

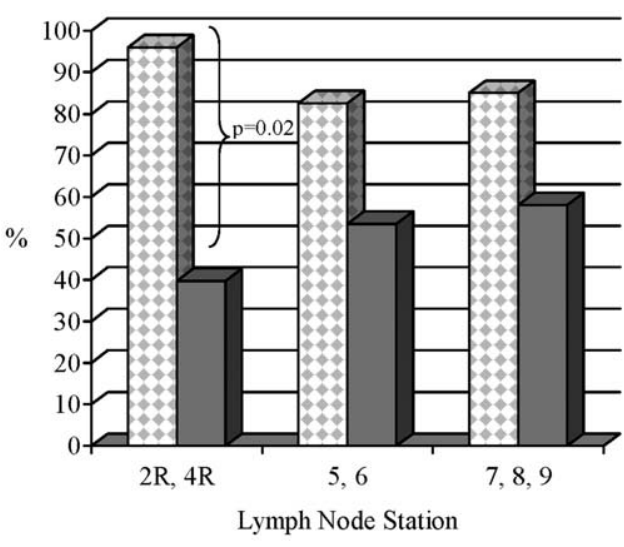

a

Figure 3. Median percentage of change in the maxSUV of N2 lymph nodes in various stations on the basis of pathologic response.

ers $(92 \%)$ and for those with stage I disease (89\%); however, it fell to only $69 \%$ for those with persistent stage III disease. Interestingly, in a parallel study that we performed (with similar methods over the same time span), we found that the accuracy of PET/CT in patients who had not had neoadjuvant therapy was not much better than it was for the patients in this study who had chemoradiotherapy. ${ }^{10}$ Reed and colleagues ${ }^{21}$ in a multi-institutional study also showed the relative inaccuracy of PET/CT in patients with NSCLC. Akhurst and colleagues (2002) ${ }^{22}$ evaluated the efficacy of repeat FDG-PET in 56 patients who had induction therapy and reported a sensitivity of $90 \%$ but a specificity of only $67 \%$.

Although repeat integrated PET/CT was better than repeat CT for the prediction of residual or benign nodal disease, false negatives and false positives were not infrequent ( $20 \%$ and $25 \%$, respectively). Thus, rebiopsy of the node, especially if the maxSUV has not fallen significantly, is mandatory. Some nodes can be rebiopsied with minimally invasive techniques such as EUS-FNA or video-assisted thoracoscopy. In this study we found the most common location of unsuspected $\mathrm{N} 2$ disease was in the 7 (subcarinal) lymph node station followed by the 5 (posterior aortopulmonary) station. Both of these lymph node stations are accessible via EUS-FNA. Thus, perhaps EUS-FNA should be considered in these patients, ${ }^{23-25}$ as well as in those who have not undergone neoadjuvant therapy, to help stage them by providing tissue. In 2003 we studied dedicated PET (not integrated PET/CT) and found that it was accurate for the $2 \mathrm{R}$ and $4 \mathrm{R}$ nodal stations after neoadjuvant therapy. ${ }^{26} \mathrm{Sim}-$ ilarly, in this study, as shown in Figure 3, the change in the maxSUV of the paratracheal lymph nodes is predictive of pathology. This finding is important clinically since this station is difficult to rebiopsy accurately with minimally 

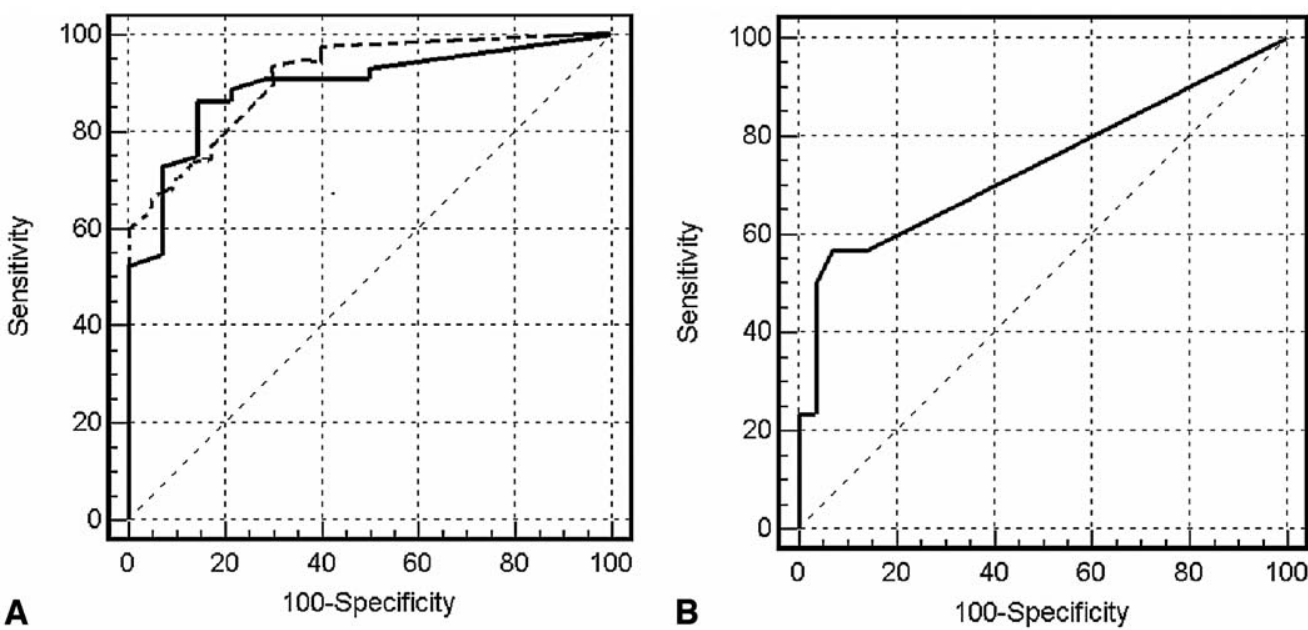

Figure 4. A, Receiver operating characteristics (ROC) curves at different cutoff points for the change in the maxSUV for complete responders, solid line $(C=0.894)$, and for partial responders, dashed line $(C=0.905)$. B, ROC curves at different cutoff points for the change in the maxSUV for initially involved N2 lymph node (C $=0.742$ ).

invasive techniques and, thus, helps guide the decision for thoracotomy. The ideal time to repeat a PET or PET/CT after radiotherapy or chemotherapy is unknown; however, in our experience we find it to be accurate between 4 and 12 weeks. Other studies have reported that a period of less than 4 weeks between the end of radiation and repeat PET scanning may interfere with test results. ${ }^{27}$

\section{MaxSUV Data}

The change in the maxSUV continues to be an important and a relatively new area of research. In this report we found that the change in the maxSUV of the primary tumor was an accurate predictor of pathologic response, which mirrors our findings in 2004 on 56 patients. ${ }^{28}$ Ryu and colleagues ${ }^{29}$ in 2002 had similar findings; however, Port and colleagues ${ }^{30}$ did not. Our consistent results may be secondary to the fact that we required both the initial and the repeat PET/CT to be performed on the same scanner with similar techniques. This approach may afford better comparison. The percentage of change and not the absolute value of the repeat PET/CT is predictive. When the maxSUV of the primary tumor decreases by $75 \%$ or more, it is highly likely (+LR, 6.1) that the patient is a complete responder. When it decreases by $55 \%$ or more, it is highly likely (+LR, 9.1) that the patient is a partial responder.

There is almost no prior literature on the issue of the change of the maxSUV of mediastinal nodes. We found that the change in the maxSUV of the initially involved lymph node also was predictive of disease. Although the percentage of decrease in the maxSUV is helpful, especially if it falls significantly, a persistently high level is not a reason to deny a patient a resection; rather, it only provides a target for a biopsy of that node. However, if the maxSUV of a node that was initially involved with metastatic cancer decreases by $\geq 50 \%$, it is highly likely ( + LR, 7.9) that the node has been rendered benign by the neoadjuvant therapy. This finding represents a powerful way to noninvasively gauge the pathologic characteristics of mediastinal nodes.

The strengths of this study are its prospective study design, the meticulous staging, the fact that all patients underwent mediastinoscopy, the limitation of confounders by having all operations performed by the same surgeon, the fact that a complete thoracic lymphadenectomy was used at the time of thoracotomy, and the use of the maxSUV for the primary tumor and the lymph nodes as opposed to the less-reproducible mean SUV. ${ }^{28}$ The limitations of this study include the fact that it was uni-institutional, 28 patients did not have pathologic confirmation after restaging, and 3 patients were lost to follow-up.

In conclusion, we found in this prospective study that repeat integrated PET/CT using FDG is superior to repeat CT for the restaging of patients with N2 stage IIIa NSCLC after neoadjuvant chemoradiotherapy. This difference achieved statistical significance for those patients with pathologic stage 0 and I disease. When the maxSUV of the primary tumor decreased by $75 \%$ or more, it is highly likely that the patient is a complete responder. When it decreased by $55 \%$ or more, it is highly likely that the patient is a partial responder. When the maxSUV of a node that was involved initially with metastatic cancer decreased by $50 \%$ or more, it is highly likely that the node has been rendered benign by the neoadjuvant therapy. A persistently high maxSUV of an initially involved mediastinal node should not be perceived 
as evidence of residual disease, but rather only as an indication for a repeat biopsy of the node. These data may help improve patient selection for thoracotomy and resection.

\section{References}

1. Mateu-Navarro M, Rami-Porta R, Bastus-Piulats R, et al. Remediastinoscopy after induction chemotherapy in non-small cell lung cancer. Ann Thorac Surg. 2000;70:391-5.

2. Van Schil P, Schoot van der J, Poniewierski J, et al. Remediastinoscopy after neoadjuvant therapy for non-small cell lung cancer. Lung Cancer. 2002;37:281-5.

3. Pitz C, Mass K, Swieten H, et al. Surgery as part of combined modality treatment in stage IIIB Non-small cell Lung Cancer. Ann Thorac Surg. 2002;74:164-9.

4. Larsen K, Krasnik M, Vilmann P, et al. Endoscopic ultrasound guided biopsy of mediastinal lesions has a major impact on patient management. Thorax. 2002;57:98-103.

5. Annema JT, Veselic M, Versteegh MI, et al. Mediastinal restaging: EUS-FNA offers a new perspective. Lung Cancer. 2003;42:311-8.

6. Cerfolio RJ, Buddhiwardhan O, Bryant AS, et al. The accuracy of integrated PET/CT compared with dedicated PET alone for the staging of patients with non-small cell lung cancer. Ann Thorac Surg. 2004; 78:1017-23.

7. Antoch G, Stattaus J, Nemat AT, et al. Non-small cell lung cancer: dual modality PET/CT in preoperative staging. Radiology. 2003;229: 525-33.

8. Lardinois D, Weder W, Hany TF, et al. Staging of non-small cell lung cancer with integrated positron emission tomography and computed tomography. N Engl J Med. 2003;348:2500-7.

9. Aquino SL, Asmuth JC, Alpert NM, et al. Improved radiologic staging of lung cancer with 2-[18]-fluoro-2-deoxy-D-glucose-positron emission tomography and computed tomography registration. J Comput Assist Tomogr. 2003;27:479-84.

10. Cerfolio RJ, Bryant AS, Ojha B, et al. Improving the inaccuracies of clinical staging of patients with NSCLC: a prospective trial. Ann Thorac Surg. 2005;80:1207-13; discussion 1213-4.

11. Mountain CF. Revisions in the international systems for staging lung cancer. Chest. 1997;111:1710-7.

12. Nabi HA, Zubeldia JM. Clinical applications of F18-FDG in oncology. J Nucl Med Technol. 2002;30:3-9.

13. Catalano MF, Sivak MV, Rice T, et al. Endosonographic features predictive of lymph node metastasis. Gastrointest Endosc. 1994;40: 442-6.

14. Ash AS, Shwarz M. Evaluating the performance of risk-adjustment methods: dichotomous outcomes. In: Iezzoni LI, editor. Risk adjustment for measuring healthcare outcomes. Chicago: Health Administration Press; 1997. p. 427-70.

15. National Cancer Institute. Surveillance, epidemiology and end results (SEER) public use data 1973-2002. Available at: http://seer.cancer. gov/publicdata. Accessed 2005.
16. Detterbeck F, Socinski M. Induction chemotherapy and surgery for I-III A, B non-small cell lung cancer. In: Detterbeck F, Socinski M, Rivera M, Rosenman J, editors. Diagnosis and treatment of lung cancer. An evidence-based guide for the practicing clinician. Philadelphia: WB Saunders Co; 2001. p. 267-82.

17. Bueno R, Richards W, Swanson S, et al. Nodal stage after induction therapy for stage IIIA lung cancer determines patient survival. Ann Thorac Surg. 2000;70:1826-31.

18. Voltolini L, Luzzi L, Ghiribelli C, et al. Results of induction chemotherapy followed by surgical resection in patients with stage IIIA (N2) non-small cell lung cancer: the importance of the nodal down-staging after chemotherapy. Eur J Cardiothorac Surg. 2001;20:1106-12.

19. Komaki R, Cox JD, Hartz AJ, et al. Characteristics of long-term survivors after treatment for inoperable carcinoma of the lung. Am J Clin Oncol. 1985:8:362-70.

20. Wallace MB, Ravenel J, Block MI, et al. Endoscopic ultrasound in lung cancer patients with a normal mediastinum on computed tomography. Ann Thorac Surg. 2004;77:1763-8.

21. Reed CM, Posther KE, Woolson SL, et al. Results of the American College of Surgeons Oncology Group Z0050 trial: the utility of positron emission tomography in staging potentially operable non-small cell lung cancer. J Thorac Cardiovasc Surg. 2003;126:1945-51.

22. Akhurst T, Downey RJ, Ginsberg MS, et al. An initial experience with FDG-PET in the imaging of residual disease after induction therapy for lung cancer. Ann Thorac Surg. 2002;73:259-66.

23. Mountain CF. Revisions in the international systems for staging lung cancer. Chest. 1997;111:1710-7.

24. Eloubeidi MA, Cerfolio RJ, Chen VK, et al. Endoscopic ultrasoundguided fine needle aspiration of mediastinal lymph nodes in patients with suspected lung cancer after positron emission tomography and computed tomography scans. Ann Thorac Surg. 2005;79:263-8.

25. Savides TJ, Perricone A. Impact of EUS-guided FNA of enlarged mediastinal lymph nodes on subsequent thoracic surgery rates. Gastrointest Endosc. 2004;60:340-6.

26. Cerfolio RJ, Ojha B, Mukherjee S, et al. Positron emission tomography scanning with 2-fluoro-2-deoxy-D-glucose as a predictor of response of neoadjuvant treatment for non-small cell carcinoma. J Thorac Cardiovasc Surg. 2003;125:938-44.

27. Haberkorn U, Strauss LG, Dimitrakopoulou A, et al. PET studies of fluorodeoxyglucose metabolism in patients with recurrent colorectal tumors receiving radiotherapy. $J$ Nucl Med. 1991;32:1485-90.

28. Cerfolio RJ, Bryant AS, Winokur TS, et al. Repeat FDG-PET after neoadjuvant therapy is a predictor of pathologic response in patients with non-small cell lung cancer. Ann Thorac Surg. 2004;78:1903-9.

29. Ryu J, Choi NC, Fischman AJ, et al. FDG-PET in staging and restaging non-small cell lung cancer after neoadjuvant chemoradiotherapy: correlation with histopathology. Lung Cancer. 2002;35:179-87.

30. Port JL, Kent MS, Korst RJ, et al. Positron emission tomography scanning poorly predicts response to preoperative chemotherapy in non-small cell lung cancer. Ann Thorac Surg. 2004;77:254-9. 